\title{
Cenário cultural de Belo Horizonte: a comunicação em cena nos palcos do teatro e da dança
}

\author{
The Belo Horizonte cultural scenario: \\ communication on scene in the theater \\ and dance stages
}

\author{
Escenario cultural de Belo Horizonte: \\ la comunicación en escena en los palcos \\ del teatro y de la danza
}

Carlos Magno Camargos Mendonça ${ }^{1}$

- Doutor em Comunicação e Semiótica pela Pontifícia Universidade Católica de São Paulo (PUC-SP)

- Mestre em Comunicação Social pela Universidade Federal de Minas Gerais (UFMG)

- Graduado em Jornalismo pela Pontifícia Universidade Católica de Minas Gerais

- Professor do Programa de Pós-Graduação em Comunicação da UFMG

- macomendonca@gmail.com

1 Este texto teve a contribuição de Caroline Moreira da Silva, bacharel em Relações Públicas pela Universidade Federal de Minas Gerais (UFMG); Danielle Marques de Almeida, bacharel em Publicidade e Propaganda pela Universidade Federal de Minas Gerais (UFMG); Felipe Carvalho Zulato, bacharel em Relações Públicas pela Universidade Federal de Minas Gerais (UFMG); Leandro Gusmão de Menezes e Renata Guimarães Figueiredo, bacharéis em Publicidade e Propaganda pela mesma instituição. Renata Figueiredo e Caroline Moreira da Silva são coautoras, junto com Marlusa Gosling, de "O impacto da qualidade percebida e da satisfação na lealdade dos clientes da Facilitta" - Revista Pretexto, Belo Horizonte, v. 9, n. 3, p. 35-58-58, jul. / set. 2008. 
Pensando a comunicação a partir de seus instrumentos de mediação e aproximação entre as manifestações culturais e o público, este artigo apresenta o processo de construção de um diagnóstico do consumo de espetáculos de teatro e dança no cenário cultural de Belo Horizonte, mapeando os públicos envolvidos e propondo diretrizes para ações de comunicação voltadas para públicos desse setor cultural.

PALAVRAS-CHAVE: CULTURA • COMUNICAÇÃO • SENSIBILIZAÇÃO

\section{Abstract}

Thinking about communication by using its instruments of mediation and approach between cultural manifestations and the public, this article presents the process for construction of a diagnosis on the consumption of theater and dance performances in the Belo Horizonte cultural scenario, mapping out the audiences involved and proposing guidelines for communication actions aimed at the publics of this cultural sector.

KEYWORDS: CULTURE • COMMUNICATION • SENSITIZATION

\section{Resumen}

Pensando la comunicación a partir de sus instrumentos de mediación y de aproximación entre las manifestaciones culturales y el público, este artículo presenta el proceso de construcción de un diagnóstico del consumo de espectáculos de teatro y de danza en el ámbito cultural de Belo Horizonte, mapea los públicos involucrados y propone directrices para acciones de comunicación dirigidas a públicos de ese sector cultural.

PALABRAS CLAVE: CULTURA • COMUNICACIÓN・SENSIBILIZACIÓN 
década de 1980 foi um marco para o setor cultural ${ }^{1}$ no Brasil. Mudanças como a criação do Ministério da Cultura, em 1985, e a promulgação da primeira legislação federal de incentivo fiscal à cultura, em 1986, permitiram o fortalecimento e a expansão do setor.

As leis de incentivo à cultura, em especial, trouxeram um aporte inédito de recursos, possibilitando a multiplicação dos equipamentos de infraestrutura culturais e um crescimento significativo no número de espetáculos realizados. Dessa forma, a cultura reposicionou seu papel estratégico na sociedade ao promover geração de emprego e renda, profissionalização, educação, turismo, crescimento econômico e inclusão social.

\section{PARA COMPREENDER O CENÁRIO}

Em Belo Horizonte, essa expansão do setor cultural pôde ser percebida, principalmente, entre 1990 e 2000 . Dados da Fundação João Pinheiro (SANTANA; SOUZA, 2001, p. 17) revelam que, em 2000, 62 mil trabalhadores tinham sua ocupação principal relacionada às atividades culturais. Esse número era superior aos da indústria metal-mecânica, têxtil e de vestuário, perdendo apenas para os 122 mil empregos da construção civil.

Apesar de não existirem dados mais recentes sobre o setor cultural belo-horizontino, pesquisas realizadas em âmbito nacional confirmam o crescimento econômico do setor no Brasil. A pesquisa "O emprego formal em atividades culturais em 2002”, realizada pelo Instituto de Pesquisa Econômica Aplicada (Ipea) mostrava que, à época, o setor cultural era responsável por 2,14\% dos empregos formais, aproximando-se do número de 741 mil trabalhadores com vínculo formal. Além disso, a mesma pesquisa chamava atenção para o fato de que o número de trabalhadores formais no segmento de espetáculos vivos (teatro e dança) era maior do que nas atividades de cinema e vídeo (2,6\% e 2,3\%, respectivamente), segmentos beneficiados pelas leis de incentivos fiscais. Já os resultados do "Sistema de informações e indicadores culturais 2003-2005" divulgados pelo Instituto Brasileiro de Geografia e Estatística (IBGE) indicam um crescimento do percentual de empresas relacionadas com as atividades culturais no período (de 5,6\% para 6,1\%). Outro dado é que, entre 2003 e 2005, o índice de trabalhadores ocupados nessas atividades manteve-se estável, com média de 5,3\%. Ainda segundo a pesquisa, e de acordo com informações do Cadastro Central de Empresas

1 Para o desenvolvimento deste artigo, baseamo-nos na concepção de setor cultural adotada pelo Instituto de Pesquisa Econômica Aplicada (Ipea) na pesquisa "0 emprego formal em atividades culturais em 2002". Segundo este documento, disponível no portal do Ipea, "o setor cultural é entendido como aquele formado por atividades relevantes para a produção e circulação de bens simbólicos. As atividades culturais são constituídas por atividades especificamente culturais (preservação, patrimônio, circo, teatro, música, escritores, bibliotecas etc.) e por outras, não culturais (funcionários, secretários, motoristas etc.), mas necessárias para o funcionamento das instituições envolvidas com a economia da cultura" (BARBOSA, 2007, p. 116). 
(Cempre), houve um maior crescimento relativo das empresas ligadas à cultura, atingindo 321 mil entidades e 1,6 milhões de trabalhadores.

Apesar de os dados apresentados confirmarem a expansão do setor cultural na capital mineira e em todo o Brasil, o sentimento do cidadão em relação à cultura deve ser considerado. O único "Diagnóstico da área cultural de Belo Horizonte" disponível, elaborado pela extinta Secretaria Municipal de Cultura e que tem por recorte o mesmo período histórico (1996), apontava como problema o acesso não-democratizado e o fato de muitos considerarem a cultura um mundo elitizado e intangível.

Os 'cidadãos comuns' sentem-se excluídos e inferiorizados frente ao mundo da cultura. É, para eles, mais uma forma de marcar as diferenças sociais. As pessoas são remetidas para o 'seu lugar'. Ao invés de criar hiatos na realidade cotidiana, através da possibilidade do prazer do entretenimento, as manifestações culturais tendem a separar e marcar ainda mais a hierarquização da sociedade. A 'posse de cultura' surge como uma marca dos segmentos de renda muito elevada da população. O mundo da cultura está sempre um degrau, ou mais, acima daquele em que o interlocutor acredita estar (PREFEITURA, 1996, p.31).

A trama da cultura é tecida por todos. Mas, a oportunidade do contato com os produtos culturais ainda está distante de muitos. Ao observar esse contexto, tornou-se evidente a importância de explorarmos mais intensamente o papel social da comunicação, utilizando seus instrumentos de mediação, a partir de suas possibilidades de aproximação entre os espectadores e as manifestações culturais. Neste artigo apresentamos o processo de construção de um diagnóstico do consumo de espetáculos de teatro e dança no cenário cultural de Belo Horizonte. Esse estudo possibilitou o mapeamento dos públicos envolvidos e a proposição de diretrizes para ações de comunicação que valorizem as manifestações culturais e que aumentem a frequência de participação do público belo-horizontino em eventos desse setor.

\section{BELO HORIZONTE: O CENÁRIO E SEUS OBJETOS}

Para conhecermos o cenário cultural de Belo Horizonte, foi necessário explorar duas dimensões essenciais e de diferentes interesses: a dimensão dos que promovem e a dos que consomem os produtos culturais.

A fim de estudarmos a realidade dos gestores, produtores, artistas e críticos culturais, optamos por entrevistas individuais a partir de um roteiro semiestruturado e flexível. Isso possibilitou que os entrevistados apresentassem de forma livre e sem constrangimentos suas percepções, críticas e sugestões acerca da cultura.

Os entrevistados foram escolhidos de acordo com sua experiência profissional e atuação em projetos, peças, grupos e/ou companhias, instituições e 
veículos de comunicação considerados importantes para o cenário cultural de Belo Horizonte.

No total, foram realizadas quinze entrevistas em profundidade, divididas em quatro categorias, no período de 16 de fevereiro a 29 de abril de 2009:

a) $\mathrm{Na}$ categoria artistas/bailarinos, foram realizadas cinco entrevistas com representantes de instituições como a Associação Brasileira de Pesquisa e Pós-Graduação em Artes Cênicas (Abrace), o Sindicato dos Artistas e Técnicos em Diversão de Minas Gerais (Sated) e o Movimento Teatro de Grupo de Minas Gerais.

b) Na categoria críticos culturais, foram ouvidos cinco profissionais com atuação nos jornais Estado de Minas, Hoje em Dia e O Tempo, além da Rádio Inconfidência.

c) Na categoria gestores culturais, foram entrevistados executivos da Associação Pró-Cultura Palácio das Artes (Appa) e do Grupo Galpão.

d) Na categoria produtores, foram ouvidos três profissionais responsáveis pelo Fórum Internacional da Dança (FID), pela Orquestra Filarmônica de Minas Gerais e pelo Encontro Mundial das Artes Cênicas (Ecum).

Em todas as entrevistas, conclamamos os entrevistados a discutir e expor suas opiniões sobre os seguintes temas: percepção geral sobre a cultura, com enfoque em teatro e dança; políticas públicas de incentivo à cultura; pontos positivos e negativos das leis de incentivo; nível de interação entre a área de cultura e outros órgãos do governo; perfil do consumidor da cultura; e, por último, a influência dos meios de comunicação no setor.

A partir da comparação das respostas, verificamos que, segundo os entrevistados:

a) A dança e o teatro são considerados as manifestações artísticas menos trabalhadas na sociedade;

b) Não existe uma política pública cultural em Belo Horizonte e em todo Brasil, mas apenas ferramentas de incentivo e fomento, que isentam, em boa parte, o Estado da sua responsabilidade de oferecer e permitir o acesso da sociedade à cultura;

c) Apesar de enviesar o patrocínio, muitos entrevistados concordam que as leis de incentivo trouxeram um alento para o setor cultural, pois permitiram mais acesso à verba das empresas privadas;

d) A relação dos órgãos de cultura com outros órgãos do governo é incipiente. Foi unanimidade a opinião de que tanto educação quanto turismo de- 
vem estar intrinsecamente conectados às manifestações culturais para, por exemplo, auxiliar na formação de público para a cultura;

e) O público belo-horizontino se interessa pelas manifestações culturais, haja vista a grande audiência da campanha de popularização do teatro e da dança que acontece na cidade. Esse interesse, no entanto, não é percebido com tanta clareza no decorrer do ano. Isso evidencia que há um potencial de consumo a ser explorado;

f) A comunicação é deixada em segundo plano pelos grupos culturais no processo de exploração de recursos. A internet, por exemplo, é pouco utilizada, apesar de ser um veículo de baixo custo e com alto potencial de repercussão.

Já em relação aos consumidores dos produtos culturais, realizamos uma pesquisa descritiva com amostra da população belo-horizontina, uma vez que não existiam estudos semelhantes com dados atualizados disponíveis. A única referência encontrada, como já citado anteriormente, foi o "Diagnóstico da área cultural de Belo Horizonte”, elaborado pela extinta Secretaria Municipal de Cultura em 1996. Esse documento foi utilizado como base comparativa para essa pesquisa.

A amostra de 300 pessoas foi baseada no número total de habitantes da cidade (dado retirado do site da Prefeitura de Belo Horizonte - 2009) e calculada, estatisticamente, com um nível de confiança de $91,5 \%$. A amostra buscou uma similaridade às características da população belo-horizontina no que diz respeito à estratificação de escolaridade, renda e idade.

O principal objetivo da pesquisa foi conhecer o perfil de consumo de produtos culturais em Belo Horizonte, especificamente espetáculos de teatro e dança. Para tanto, elaboramos um questionário fechado estruturado com vinte e quatro questões. Esse questionário foi aplicado em locais com grande fluxo de pessoas, como shoppings centers, terminais rodoviários e estações de metrô. Isso indica que o elemento pesquisado foi autosselecionado ou selecionado por estar disponível no local e no momento em que a pesquisa foi realizada.

Os dados obtidos com a aplicação dos questionários foram analisados com o auxílio do software SPSS ${ }^{2}$. São alguns dos principais resultados:

a) $86 \%$ dos entrevistados já foram a um espetáculo de teatro, mas apenas $54 \%$ frequentaram um espetáculo de dança. Essas percentagens são significativamente maiores do que as encontradas em 1996. Naquele ano, apenas

20 Statistical Package for the Social Sciences (SPSS) é um software de análise estatística. Criado em 1968, é um dos softwares mais utilizados no campo das ciências sociais e na realização de pesquisas de mercado. 0 aplicativo possibilita testes estatísticos como os de correlação e de hipóteses, além de contagens de freqüências, e possui aplicações analíticas como Data Mining e Text Minig. 
$31 \%$ já haviam ido alguma vez ao teatro e $20 \%$ a um espetáculo de dança. Além disso, foi possível inferir que, quanto maior a escolaridade, maior o número de pessoas que já foram ao teatro e à dança;

b) Assim como em 1996, os amigos são os principais motivadores para a frequência em espetáculos de teatro e dança. Entretanto, naquele ano, os professores ocupavam o terceiro lugar no grau de influência. Atualmente, figuram o quarto lugar, com apenas 3\% das citações. Isso explicita uma realidade importante: a escola deixou de ser um dos grandes locais de formação e influência, cedendo ainda mais espaço para as relações sociais dadas com amigos, parceiros e familiares.

\section{Gráfico 1 - Quem mais te motiva a ir a um espetáculo de:}

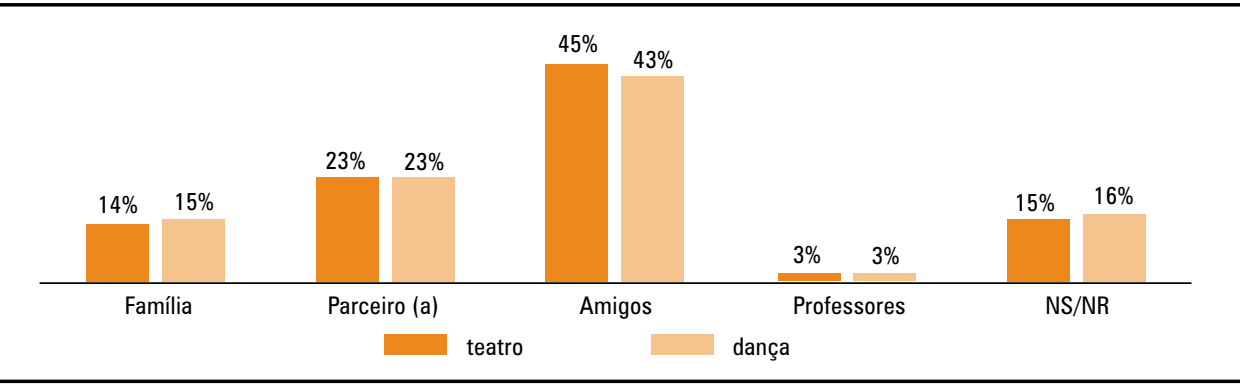

c) Houve um declínio da percentagem da população que não gosta de teatro e/ou não se interessa por ele. Enquanto esse percentual era de $45 \% \mathrm{em}$ 1996, na presente pesquisa o índice caiu para 35\%. Em contrapartida, a percentagem de quem não aprecia espetáculos de dança ou não tem interesse por eles aumentou de $41 \%$ para $46 \%$. Notamos ainda que o problema de divulgação dos espetáculos de dança persiste há mais de uma década, já que, em 1996, 23\% disseram não ir aos espetáculos por não receberem informações. Esse indicador se manteve pouco alterado, representando $20 \%$ das respostas na atual pesquisa.

Gráfico 2 - Por que você nunca foi a um espetáculo de:

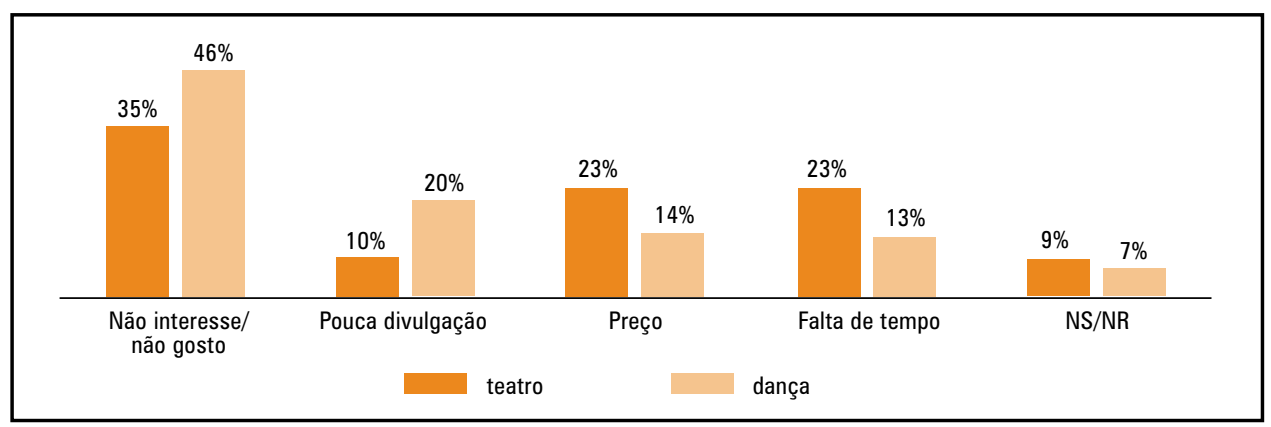


d) O público totalmente indiferente ao teatro e à dança reduziu-se consideravelmente. Em 1996, cerca de 30\% dos entrevistados disseram que nada poderia ser feito para que passassem a frequentar os espetáculos. Atualmente, esse percentual equivale a $9 \%$ para o teatro e $17 \%$ para a dança. No caso do teatro, houve ainda um aumento no número de pessoas que indicaram a motivação/companhia como fator determinante para frequentar espetáculos. Em 1996, essa percentagem equivalia a 3\% dos entrevistados, contra $16 \%$ indicados nesta pesquisa. Já em relação à dança, a motivação/companhia aparece como o principal fator a ser explorado.

\section{Gráfico 3 - 0 que poderia ser feito para que você frequentasse espetáculo de:}

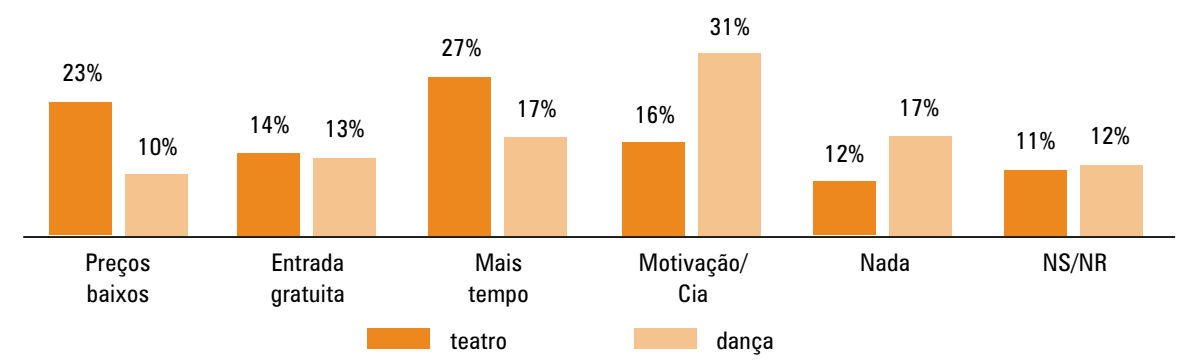

e) Em relação aos meios pelos quais se informam, é possível perceber algumas mudanças de hábitos. Em 1996, a televisão também era o principal meio de informação e o jornal, que aparecia em segundo lugar (cerca de $25 \%$ de citações), agora ocupa a $4^{\text {a }}$ posição com um percentual de $10 \%$. Um ponto positivo a ser observado é a redução da percentagem que não procura se informar de 30\% (em 1996) para 8\%. Apesar de a internet não ter sido citada na pesquisa de 1996, hoje ela é o segundo meio de informação mais utilizado.

\section{Gráfico 4 - Como você fica sabendo de espetáculos de teatro e dança em BH?}

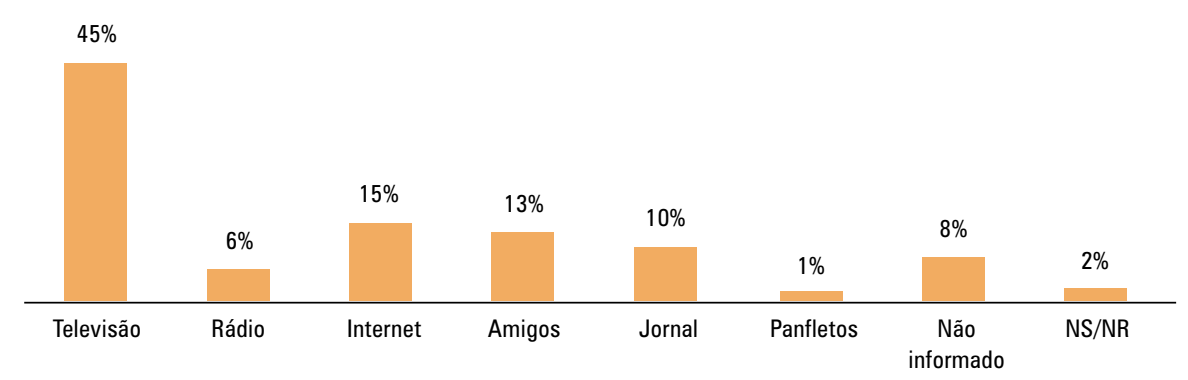


A convergência dos resultados da pesquisa quantitativa com as conclusões obtidas na pesquisa qualitativa nos permite estabelecer questões centrais para este diagnóstico.

A primeira delas trata da escola como local de formação de público. De acordo com as pesquisas, a escolaridade tem influência direta na freuência a espetáculos. No entanto, aferidas as respostas, percebe-se que as instituições de ensino deixaram de ser um local de motivação. Isso pode ser explicado pela ausência de parcerias entre órgãos de cultura e outros órgãos do governo para auxiliar na formação de público para a cultura, como, por exemplo, parceria com as secretarias de Educação. Outro fator que contribui para agravar tal situação é a inexistência de políticas públicas para a cultura que permitam o acesso da sociedade às manifestações culturais. Tais deficiências evidenciam a necessidade do estreitamento das relações entre as áreas de cultura e educação com o auxílio do Estado.

A segunda questão diz respeito à importância dos amigos como motivadores/ companhia para a frequência em espetáculos. As pesquisas mostraram que o público belo-horizontino está mais interessado pelas manifestações culturais. No entanto, ele necessita de motivação que, na maioria das vezes, vem dos amigos. Atualmente, a internet é um lugar de encontro. Com o advento das redes sociais, o internauta pode se tornar um produtor e multiplicador de conteúdo em potencial. As novas possibilidades desse meio ainda pouco utilizado pelo setor cultural devem, portanto, ser consideradas, a fim de se explorar os amigos como fator motivacional para a ida a espetáculos.

A última questão se refere à utilização dos meios de comunicação pelos artistas e grupos culturais. Devido à escassez de recursos, a comunicação representa um gasto secundário no orçamento. No entanto, a falta de informação é fator determinante para a baixa frequência do público nos espetáculos. Nesse cenário, é preciso considerar que, apesar de a televisão ser o meio pelo qual as pessoas mais se informam, seu custo de veiculação é elevado. Já a internet, que ocupa a segunda posição, representa uma opção acessível de divulgação por ser um meio de baixo custo com grande potencial de alcance.

\section{O MAPEAMENTO DOS PÚBLICOS}

Após aferirmos os elementos que compõem uma parcela do cenário cultural em Belo Horizonte, percebemos o quanto a comunicação é negligenciada no processo de promoção do espetáculo vivo na cidade. Ao visualizarmos os comportamentos e as expectativas dos entrevistados, verificamos a necessidade de se estabelecerem estratégias de comunicação e abordagens direcionadas. Para isso, mapeamos os públicos envolvidos com a cultura na tentativa de identificarmos os reais e/ou potenciais "consumidores culturais" da capital mineira. 
Para a elaboração do mapa de públicos, abandonamos a divisão tradicional entre públicos interno, externo e misto e utilizamos a "conceituação lógica de públicos”, cunhada por Fábio França (2008). Essa metodologia permitiu a contemplação de sistemas de relacionamentos mais complexos, com base nos objetivos e nos critérios de dependência, participação e interferência de cada relacionamento. Dessa forma, observamos amplamente a relação que cada público mantém com a cultura, facilitando a visualização dos fluxos de comunicação existentes.

A fim de facilitar a visualização dos públicos e seus vínculos com o setor cultural, elaboramos o gráfico abaixo:

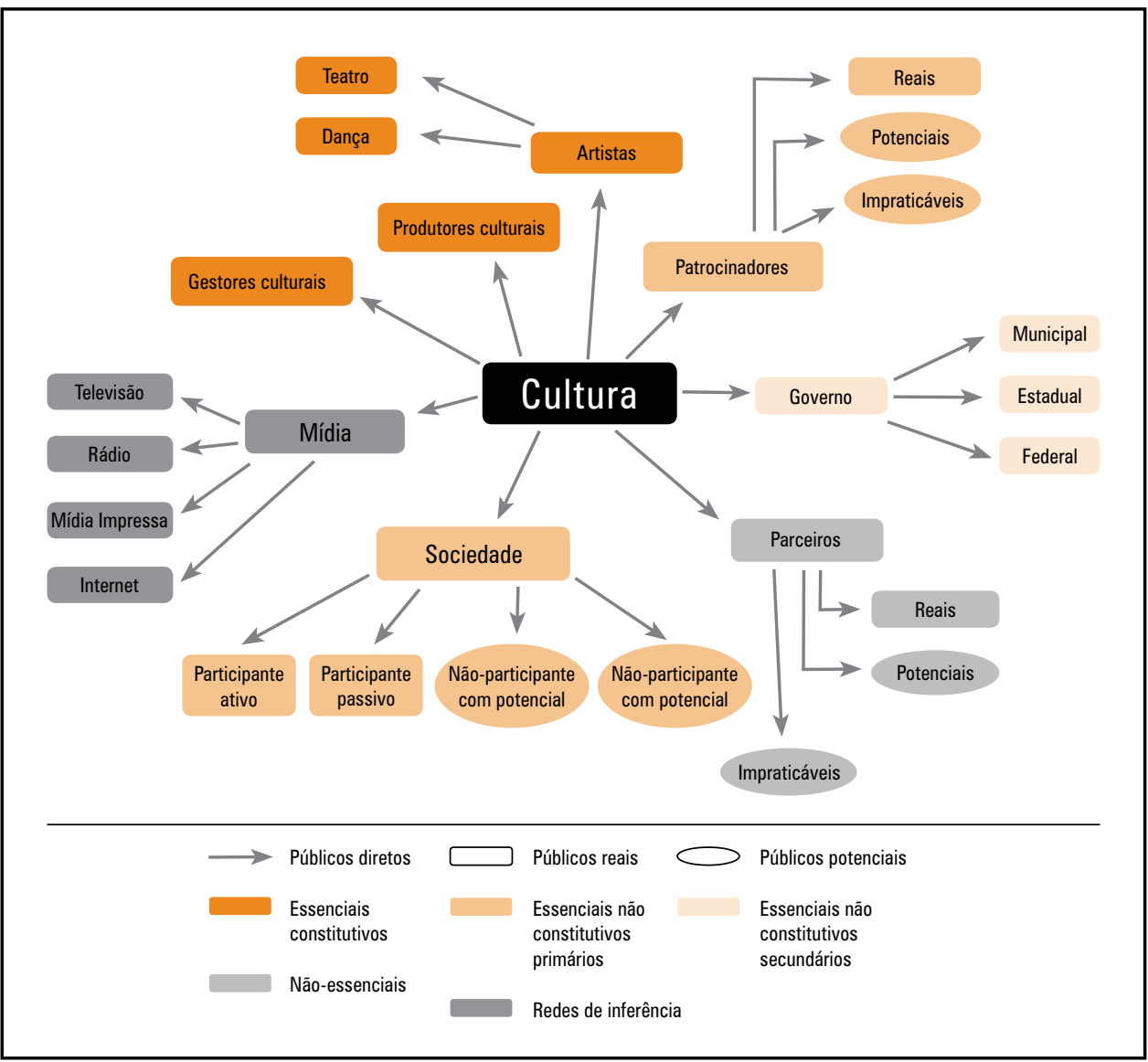

\section{CONSIDERAÇÕES FINAIS}

O diagnóstico do consumo de espetáculos de teatro e dança no cenário cultural de Belo Horizonte demonstra que, além de a comunicação não ser explorada em todo o seu potencial a favor do setor, o acesso da população às manifestações culturais é dificultado pela falta de informação/divulgação. Dessa 
forma, utilizar os instrumentos de comunicação para mediar e aproximar as manifestações culturais e o público implica, essencialmente, promover maior visibilidade midiática para a cultura.

Segundo Mafra (2006, p. 54), a mídia, a partir da sua dimensão "espetacular", é capaz de "chamar a atenção, despertar o interesse, capturar a atenção dos sujeitos; sair do ordinário; promover existência pública às causas sociais”.

Podemos citar pelo menos quatro razões que justificam a importância de a cultura estar na mídia:

a) Garantir sobrevivência: a exposição garante a manutenção de uma instituição, organização ou grupo devido ao interesse público que desperta;

b) Ganhar apoio para obter recursos: a exposição midiática é capaz de sensibilizar os públicos envolvidos, o que representa grandes chances de se conquistar novos parceiros;

c) Prestar contas à sociedade (accountability): estar na mídia possibilita à sociedade avaliar o que está sendo feito na área da cultura, refletir sobre o assunto e criticar a viabilização de dinheiro público, já que a grande maioria das apresentações é obtida por meio de renúncia fiscal;

d) Valorização das atividades culturais: ao compreender a importância do tema, a sociedade valoriza, defende e cobra investimentos na área.

Ao estabelecermos como objetivo principal da comunicação dar visibilidade midiática à cultura, traçamos três diretrizes norteadoras para o setor cultural de Belo Horizonte:

I. A sensibilização da sociedade para a cultura;

II. A busca por parcerias entre os órgãos de Cultura e demais Secretarias do Governo;

III. A sensibilização de patrocinadores para fomento às manifestações culturais.

Tais diretrizes podem ser contempladas por meio de ações de comunicação direcionadas para os públicos envolvidos direta ou indiretamente com o setor cultural, por exemplo:

1) Diretriz I

a) A utilização de mídias sociais e a produção de virais é uma forma de aliar o baixo custo de veiculação da internet à possibilidade de se explorarem os amigos como motivadores de ida aos espetáculos;

b) O oferecimento de espetáculos gratuitos previamente divulgados nos centros culturais da capital e a realização de espetáculos e/ ou esquetes em lugares públicos podem auxiliar na sensibilização e na formação de público; 
c) A utilização de mídia de banheiros de bares é uma maneira de explorar a fama internacional de Belo Horizonte de capital mundial dos 'butecos' a favor das manifestações culturais.

\section{2) Diretriz II}

A criação de projetos interdisciplinares entre órgãos de cultura e outras secretarias com o intuito de formar público para a cultura. Por exemplo, a realização de espetáculos de teatro e dança mensalmente e/ ou a criação de núcleos de teatro infantil nas escolas da rede pública de ensino.

\section{3) Diretriz III}

A criação de uma "feira de negócios culturais" é uma oportunidade para o contato direto entre artistas/grupos e potenciais patrocinadores, o que aumenta a possibilidade de parcerias.

Por fim, a observação do cenário de consumo de espetáculos de teatro e dança em Belo Horizonte nos possibilita ainda refletir sobre as transformações das relações sociais desencadeadas pelo surgimento de novos meios de produção e circulação das formas simbólicas da sociedade. Segundo Henriques (2005), a invenção do jornal, do rádio, da televisão e, mais recentemente, da internet fez surgir novas formas de inter-relacionamento, alterando até mesmo a organização do tempo e do espaço. É a existência desse variado mix de meios e canais que possibilita à comunicação assumir um papel estratégico, servindo não apenas para dar visibilidade a uma causa, mas também criar vínculo entre os sujeitos e a causa defendida.

Na geração desse vínculo, os esforços comunicacionais não operam necessariamente na utilização de meios de maior alcance (mídia massiva), mas sim de instrumentos de comunicação dirigida capazes de produzir maior identificação e grau de personalização. No caso do setor cultural, portanto, em que informação e motivação podem ampliar o alcance dos produtos culturais, as ações de comunicação dirigida devem funcionar como catalisadores na democratização do acesso à cultura, promovendo mudanças de atitude que contribuam para a formação e consolidação do público em Belo Horizonte.

\section{REFERÊNCIAS BIBLIOGRÁFICAS}

AVELAR, Rômulo. 0 avesso da cena: notas sobre produção e gestão cultural. Belo Horizonte: Duo Editorial, 2008.

BARBOSA, Frederico. 0 emprego formal em atividades culturais em 2002. In: BRASIL. Ministério da Cultura / Instituto de Pesquisas Econômicas. Economia e política cultural: acesso, emprego e financiamento. Brasília: Ministério da Cultura, 2007. p. 113-134. (Cadernos de Políticas Culturais, v. 3). Disponível em: < http://www.ipea.gov.br/sites/000/2/livros/cardenosdepoliticas/cadvol3.pdf>.

BARROSO, Bruno et al. Portal Híbrida Cultura. 2008. 137 f. Projeto experimental (Graduação em Comunicação Social) - Universidade Federal de Minas Gerais, Belo Horizonte. 
BRASIL. Ministério da Cultura / Instituto de Pesquisas Econômicas. Economia e política cultural: acesso, emprego e financiamento. Brasília: Ministério da Cultura, 2007. p. 113-134.

COSTA, Ivan Freitas. Marketing cultural: o patrocínio de atividades culturais como ferramenta de construção de marca. São Paulo: Atlas, 2004.

FRANÇA, Fábio. Públicos: como identificá-los em uma nova visão estratégica. São Caetano do Sul, SP: Yendis Editora, 2008.

HENRIQUES, Márcio S. Comunicação, comunidades e os desafios da mobilização social. In: CONGRESSO BRASILEIRO DE CIÊNCIAS DA COMUNICAÇÃO, XXVIII, Rio de Janeiro, 2005. Trabalho apresentado ao NP - de Comunicação para a Cidadania. São Paulo: Intercom, 2005. (CD).

IBGE - Instituto Brasileiro de Geografia E Estatística. Sistema de informações e indicadores culturais 2003-2005. Rio de Janeiro: IBGE, 2007. Disponível em:<http://www.ibge.gov.br/home/estatistica/populacao/indic_culturais/2005/indic_culturais2005. pdf $>$. Acesso em: 01 fev. 2009.

KOTLER, Philip; KELLER, Kevin Lane. Administração de marketing. São Paulo: Pearson / Prentice Hall, 2006.

KUNSCH, Margarida M. Krohling. Planejamento de relações públicas na comunicação integrada. 4. ed. - rev., atual. e ampl. São Paulo: Summus Editorial, 2003.

MAFRA, Rennan. Entre o espetáculo, a festa e a argumentação: mídia, comunicação estratégica e mobilização social. Belo Horizonte: Autêntica, 2006.

MALHOTRA, Naresh K. Pesquisa de marketing: uma orientação aplicada. Porto Alegre: Bookman, 2001.

PREFEITURA DE BELO HORIZONTE. Anuário estatístico de Belo Horizonte. 2003. Disponível em: < portalpbh.pbh.gov.br/pbh>. Acesso em: 01 mar. 2009.

Primeiro diagnóstico da área cultural de Belo Horizonte. Belo Horizonte: Secretaria Municipal de Cultura, 1996.

SOUZA, Nícia Raies Moura; SANTANA, Sylvana de Castro Pessoa. Além da diversão e arte, o pão: o mercado de trabalho da cultura na região metropolitana de Belo Horizonte. Belo Horizonte: Fundação João Pinheiro, 2001.

Recebido em: 29.06.2010 / Aceito em: 27.08.2010 